\title{
Prevalence and Antimicrobial Susceptibility Pattern of Extended Spectrum Beta-Lactamse Producing Escherichia coli and Klebsiella pneumoniae Isolated at a Tertiary Care Institute in North West Region of Rajasthan, India
}

\author{
Bhagirath Ram Bishnoi $^{1}$, Abhishek Binnani ${ }^{1}$ and Priyanka Soni Gupta ${ }^{2} *$ \\ ${ }^{1}$ Department of Microbiology, S. P. Medical College, Bikaner, Rajasthan, India \\ ${ }^{2}$ Department of Microbiology, Jawahar Lal Nehru Medical College, Ajmer, Rajasthan, India \\ *Corresponding author
}

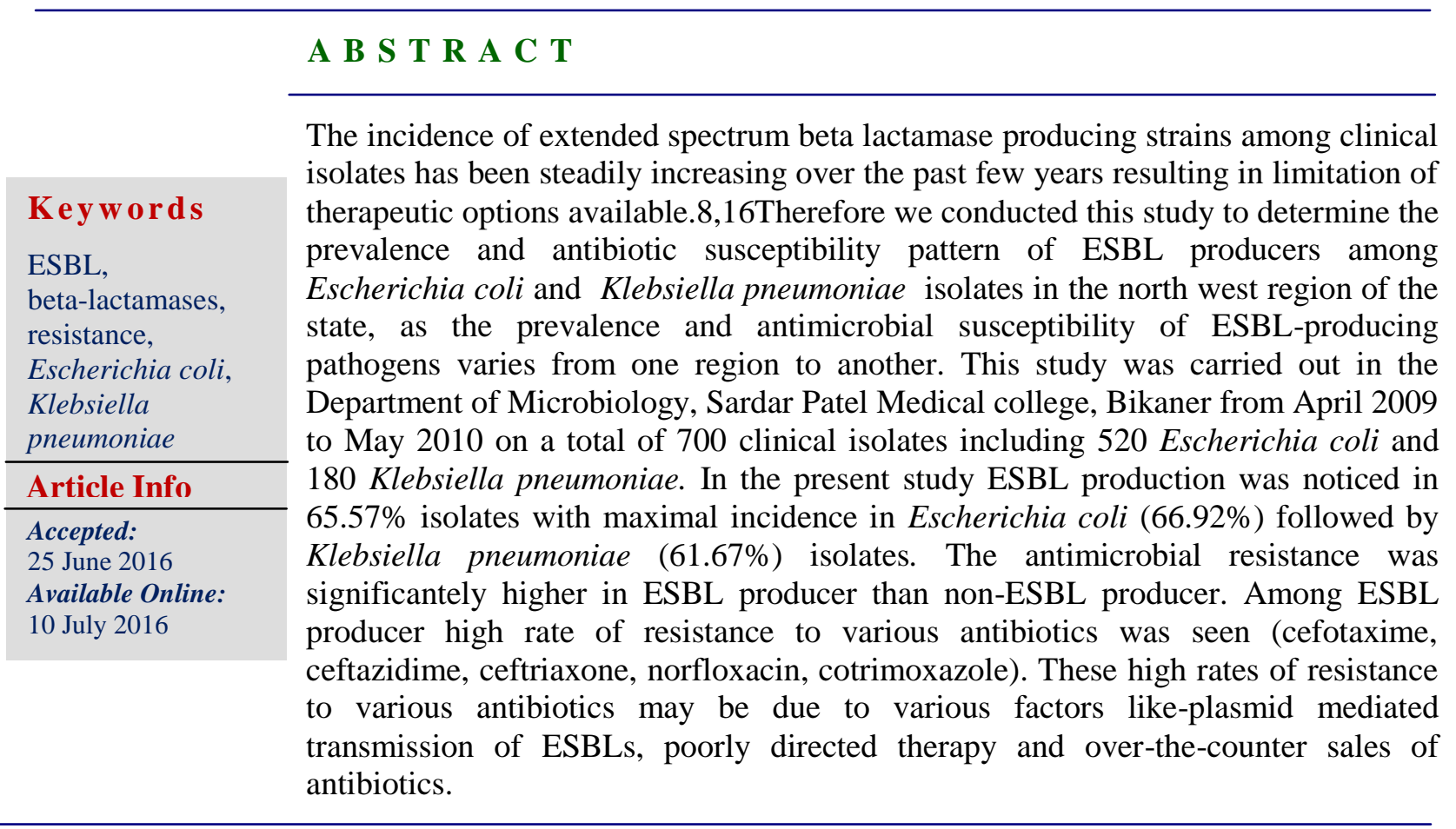

\section{Introduction}

Resistant bacteria are emerging world wide as a threat to the favourable outcome of common infections in the community and hospital settings. $\beta$-lactamases production by several gram negative and gram positive organisms is perhaps the most important single mechanism of resistance to penicillins and cephalosporins. In the past it was believed that cephalosporins were relatively immune to attack by $\beta$-lactamases, but latter on Klebsiella spp. was found to be resistant to cephalosporin. The mechanism of this resistance was production of extended spectrum $\beta$-lactamases (ESBLs) (Chaudhary et al., 2004).

Over the last 20 years, many new $\beta$-lactam antibiotics have been developed that were 
specifically designed to be resistant to the hydrolytic action of $\beta$-lactamases. However, with each new class that has been used to treat patients, new $\beta$-lactamases emerged that caused resistance to that class of the drug. Presumably, the selective pressure of the use and overuse of new antibiotics in the treatment of patients has selected for new variants of $\beta$-lactamase. One of these new classes was the oxyimino-cephalosporins, which became widely used for the treatment of serious infections due to gram-negative bacteria in the 1980s. Not surprisingly, resistance to these expanded-spectrum $\beta$ lactam antibiotics due to $\beta$-lactamases emerged quickly (Bradford, 2003).

Extended spectrum beta-lactamases (ESBLs) represent a major group of of $\beta$ lactamases currently being identified world wide in large numbers, most commonly produced by Klebsiella pneumoniae and Escherichia coli but also occur in other gram negative bacteria (Agrawal et al., 2008; Kumar et al., 2006; Rodrigues et al., 2004).

ESBLs are derivative of common betalactamases that have undergone one or more amino acid substitution near the active site of enzyme, thereby increasing their affinity and hydrolytic activity against third generation cephalosporins and monobactams. However these plasmid mediated enzyme have no detectable activity against carbapenems (Kader et al., 2005; Shobha et al., 2009; Bishara et al., 2005; Briggs et al., 2005).

Being plasmid mediated they are easily transmitted among members of Enterobacteriace thus facilitating the dissemination of resistance not only to $\beta$ lactam but to other commonly used antibiotics such as quinolones and aminoglycosides.
ESBLs are specifically inhibited by $\beta$ lactamase inhibitors like clavulanic acid, and this property is commonly utilized for the detection and confirmation of ESBLs in the laboratory (Agrawal et al., 2008; Tsering et al., 2009).

As no enough study has been undertaken on prevalence and antibiotic susceptibility pattern of ESBL producing Escherichia coli and Klebsiella pneumoniae in the state of Rajasthan, with the prevalence and antimicrobial susceptibility of ESBLproducing pathogens varying from one region to another, therefore we conducted this study to determine the prevalence and antibiotic susceptibility pattern of ESBL producers among Escherichia coli and Klebsiella pneumoniae isolates in the north west region of the state.

\section{Materials and Methods}

This study was carried out in the Department of Microbiology, Sardar Patel Medical college, Bikaner from April 2009 to May 2010 to detect Extended spectrum betalactamase producing strains of Escherichia coli and Klebsiella pneumoniae in a total of 700 clinical isolates. 520 Escherichia coli and 180 Klebsiella pneumoniae were isolated from various clinical specimens such as urine, blood, pus, wound, sputum and other respiratory tract specimen, body fluids, high vaginal swab, stool, semen, prostatic secretion and CSF etc. received from patients attending various outpatient departments, admitted in wards at P.B.M. hospital and associated group of hospitals.

\section{Inclusion Criteria}

All consecutive, non-duplicate isolates of Escherichia coli and Klebsiella pneumoniae were collected from various clinical specimens. 
Medical and demographic data of the patients were collected using a questionnaire. Data recorded were: demographic characteristics (age, gender); underlying lung diseases, acute suppurative otitis media, diabetes mellitus, chronic renal failure, nephrotic syndrome, connective tissue disease, malignancy, immuno-compromisation, septicemia, burn, eclampsia, puerperal sepsis. pyometra, peritonitis, fractures etc. Presence of intravascular or urinary catheters; prolong hospitalization (> one week); history of intensive care unit (ICU) stay; nursing home residency; being on mechanical ventilation; prior antibiotic use ; and recent surgery (within one month); poor nutritional status; haemodialysis etc. were also noted.

\section{Exclusion Criteria}

Isolation of three organism types with no predominating organism and repeated isolate from same patient were excluded from this study.

The samples were processed for the identification of organisms on the basis of conventional microbiological procedures and were screened for ESBLs. All isolates were cultured on Mac Conkey Agar and Blood Agar and urinary isolates on Hichrome UTI media (obtained from HiMedia, Mumbai, India) also and incubated at $37^{\circ} \mathrm{C}$ for $24 \mathrm{hrs}$. They were identified to species level by their characteristic appearances on the media, Gram's stain, Oxidase test, Motility and the pattern of the biochemical reactions. Flow chart was used for preliminary identification of organisms as shown in chart 1

Antimicrobial susceptibility of the various isolates was performed as per the Clinical and Laboratory Standards Institute (CLSI) guidelines by the Kirby Bauer disk diffusion method on Mueller Hinton agar with a 0.5
McFarland's turbid inoculum as per CLSI recommendation (CLSI).

The zone of inhibition was measured and reported as Susceptible, Intermediate or Resistant according to standard zone size. For statistical purposes, data were categorized as susceptible and nonsusceptible (including intermediate and resistant groups).

Control: Escherichia coli ATCC 25922 \& Staphylococcus aureus ATCC 25923

Following antibiotic discs (obtained from Hi-Media, Mumbai, India) were used for antimicrobial sensitivity testing: Amikacin (30 $\mu \mathrm{g})$, Amoxicillin+Clavulanic acid (20/10 $\mu \mathrm{g})$, Cefotaxime $(30 \mu \mathrm{g})$, Ceftazidime (30 $\mu \mathrm{g})$, Ceftriaxone $(30 \mu \mathrm{g})$, Cotrimoxazole $(1.25 / 23.75 \mu \mathrm{g})$, Doxycycline hydrchloride (30 $\mu \mathrm{g})$, Gatifloxacin $(5 \mu \mathrm{g})$, Imipenem $(10 \mu \mathrm{g})$, Meropenem (10 $\mu \mathrm{g})$, Nitrofurantoin (300 $\mu \mathrm{g})$, Norfloxacin $(10 \mu \mathrm{g})$

The inhibition zone diameter was measured in $\mathrm{mm}$ with the help of a special measuring scale and results recorded for each isolate separately as Sensitive, resistant, intermediate $(S, R, I)$ according to the given standard zone size below for enterobacteriaceae.

Screening and confirmation of ESBL production by the phenotypic confirmatory (combination disc method) test was done as per the guidelines recommended by CLSI. Control strains, Escherichia coli ATCC 25922 (Beta-Lactamase negative) and Klebsiella pneumoniae ATCC 700603 (ESBL positive) were used for quality control.

Initial Screening Tests (Agrawal et al., 2008; Winn et al., 2006): Inoculum was prepared by suspending few colonies of test 
strain in $0.9 \%$ sterile saline and turbidity was adjusted to $0.5 \mathrm{Mc}$ Farland turbidity tube. A lawn culture was made from the inoculum using a sterile cotton swab on the surface of Mueller-Hinton agar medium and Ceftazidime $(30 \mu \mathrm{g})$ and Cefotaxime $(30 \mu \mathrm{g})$ discs were applied with all sterile precautions. The plates were incubated for $18-24$ hours at $37^{\circ} \mathrm{C}$.

According to the CLSI guidelines, isolates showing inhibition zone size of $\leq 22 \mathrm{~mm}$ with Ceftazidime $(30 \mu \mathrm{g})$ and $\leq 27 \mathrm{~mm}$ with Cefotaxime $(30 \mu \mathrm{g})$ were identified as potential ESBL producers and shortlisted for confirmation of ESBL production.

Phenotypic confirmatory test with combination disc: In this test, a thirdgeneration cephalosporin, Ceftazidime $(30 \mu \mathrm{g})$ alone and in combination with clavulanic acid $(10 \mu \mathrm{g})$ was used. Both the discs were placed at least $25 \mathrm{~mm}$ apart, center to center, on a lawn culture of the test isolate on Mueller Hinton Agar (MHA) plate and incubated overnight at $37^{\circ} \mathrm{C}$. Difference in zone diameters with and without clavulanic acid was measured.

When there was an increase of $\geq 5 \mathrm{~mm}$ in inhibition zone diameter around combination disk of Ceftazidime + Clavulanic acid versus the inhibition zone diameter around Ceftazidime disc alone, was considered as confirmed ESBL producer.

\section{Results and Discussion}

Out of 700 isolates of Escherichia coli and Klebsiella pneumoniae, 459 (65.57\%) were found ESBLs producers. Out of 520 Escherichia coli isolates 348 (66.92\%) were found ESBLs producers and of the 180 Klebsiella pneumoniae isolates 111 $(61.67 \%)$ were found ESBLs producers.
ESBL producing E. coli \& K. pneumoniae strains were most frequently recovered from urine $62.36 \%(217 / 348), 32.43 \%$ (36/111) followed by sputum \& respiratory tract specimens $15.23 \% \quad(53 / 348), \quad 27.03 \%$ (30/111) respectively.

During past 60 years, bacteria have demonstrated a remarkable ability to resist almost every antibiotic that has been developed.(11,12,13) Extended spectrum beta-lactamases (ESBLs) represent a major group of beta-lactamases, currently being identified worldwide in large numbers, most commonly produced by Klebsiella pneumoniae and Escherichia coli.

The present study was conducted on 700 clinical isolates (520 Escherichia coli and 180 Klebsiella pneumoniae ) recovered from various clinical specimens, from all ages and both sexes attending various outpatient departments and admitted in wards at P.B.M. hospital and associated group of hospitals.

ESBL production was noticed in $65.57 \%$ isolates with maximal incidence in Escherichia coli (66.92\%) followed by Klebsiella pneumoniae (61.67\%). This high incidence of ESBL production agrees with Mohanty S et al., (2003)(18) where ESBL strains were observed in $71.5 \%$ isolates (60.7\% Escherichia coli and $78.7 \%$ Klebsiella pneumoniae), Rajini E et al., (2008)( Rajini et al., 2008) where ESBL production was noticed in $57 \%$ isolates ( $E$. coli $72 \%$ followed by Klebsiella pneumoniae $38.4 \%$ ), Sasirekha B et al., (2010)( Sasirekha et al., 2010)where 53.9\% isolates were found to be ESBL producer (61.1\% E.coli followed by $K$. pneumoniae $40.6 \%)$.

ESBL-producing E. coli strains were recovered most frequently from urine 
(62.36\%) followed by sputum \& Respiratory tract specimens $(15.23 \%)$ and pus \& other wound discharges $(13.79 \%)$ (Table -2). Similar observations were made by Sasirekha et al., (2010) where ESBL producing $E$. coli were most frequently obtained from urine $(76 \%)$ followed by sputum (18.7\%) and pus (5.2\%), Wani K A et al., (2009) ESBL producing E. coli isolates were most commonly recovered from urine $(72.9 \%)$ followed by pus $9.3 \%$ and blood $7.6 \%$, Agarwal P et al., (2008) with ESBL-positive isolates highest among urinary isolates $(70 \%)$ followed by pus $(22.5 \%)$ and blood (5\%).

ESBL-producing $K$. pneumoniae strains were recovered most frequently from urine (32.43\%) followed by sputum \& Respiratory tract specimens $(27.03 \%)$, pus \& other wound discharges (26.13\%) and blood $(6.31 \%)$ (table.3). Similar observations were made by Sasirekha et al., (2010) who reported maximum incidence in urine $(60 \%)$ followed by sputum (28.5\%) and pus (11.4\%), Kusum et al., (2004) reported urine (44\%) followed by sputum (42\%) and blood (14\%). In other studies, Waiwarawooth et al., (2006) reported higher incidence of ESBL production in sputum (44.69\%), followed by urine $(21.60 \%)$, pus $(18.24 \%)$ and blood (10.28\%) and El Astal et al., (2008) higher incidence in pus (48.4\%) followed by urine $(25.8 \%)$, sputum $(17.2 \%)$ and blood $(5.7 \%)$.

In the present study ESBL producing E. coli isolates were found to be $100 \%$ susceptibile to imipenem \& meropenem similar to observations made by Agarwal et al., (2008), El Astal et al., (2008), Fazlay Bazzaz et al., (2009), Wani et al., (2009) and Sasirekha et al., (2010). 60.35\% ESBL producing $E$. coli isolates were found to be susceptible to amikacin, with variable susceptibility observed in other studies as
Bishara et al., (2005) 75\%, El Astal et al., (2008) $77.8 \%$ and Wani et al., (2009) $78.2 \%$. ESBL producing E. coli isolates from urine showed $69.12 \%$ susceptibility to nitrofurantoin slightly on lower side as compared to other studies Puberza et al., (2007) 92.3\% and Wani et al., (2009) 91.5\% . Susceptibility to gatifloxacin was seen in $51.44 \%$ of ESBL producing E. coli isolates while Wani et al., (2009) observed $64.1 \%$ susceptibility. $20.11 \%$ susceptibility to doxycycline hydrochloride was reported which agrees with El Astal et al., (2008) reporting $22.2 \% \quad$ susceptibility. Cotrimoxazole susceptibility was seen in $11.21 \%$ of ESBL producing $E$. coli isolates with variation in other studies like Tsering DC et al., (2009) 21.52\%, El Astal et al., (2008) 22.2\% and Shobha et al., (2007) 42\%. $32.5 \%$ ESBL producing E. coli isolates were found to be susceptible to amoxicillin+clavulanic acid similar to the studies by Bishara et al., (2005) 33\%, Gupta et al., (2007) 31\%, El Astal et al., (2008) $22.2 \%$. High resistance to norfloxacin of $0.92 \%$ was seen in ESBL producing E. coli isolates from urine with other studies showing higher susceptibility. High resistance was also shown for III $^{\text {rd }}$ generation cephalosporin with only $0.86 \%$ and $0.29 \%$ ESBL producing $E$. coli being susceptibile to ceftriaxone and cefotaxime, respectively while all strains being resistant to ceftazidime. This corresponds to study of $\mathrm{El}$ Astal et al., (2008) where none of the tested isolates were susceptible to cephalosporins and Wani et al., (2009) who reported 0.8\%, $0.8 \%, 2.5 \%$ susceptibility of cefotaxime, ceftazidime and ceftriaxone respectively.

ESBL producing $K$. pneumoniae isolates were found to be $100 \%$ susceptible to imipenem \& meropenem similar to observations made by Gupta et al., (2007), El Astal et al., (2008), Fazlay Bazzaz et al., (2009), Mehrgan et al., (2010). 55.86\% 
ESBL producing $K$. pneumoniae isolates were found to be susceptibile to amikacin which agrees with observations made by Agarwal et al., (2008) 44\%, and El Astal et al., (2008) 67.5\%. ESBL producing $K$. pneumoniae isolates from urine showed $66.67 \%$ susceptibility to nitrofurantoin which was also observed by Mehrgan et al., (2010) 60\% and Puberza et al., (2007) $72.2 \%$ respectively. $63.03 \%$ susceptibility to gatifloxacin was seen in ESBL producing $K$. pneumoniae isolates. $27.03 \%$ of ESBL producing $K$. pneumoniae isolates were susceptibile to doxycycline hydrochloride similar to El Astal et al., (2008) who reported $20 \%$ susceptibility. $5.41 \%$ susceptibility to cotrimoxazole was observed in ESBL producing $K$. pneumoniae isolates with marked variation in other studies like Brigg et al., (2005) 5\%, Tsering et al., (2009) 21.52\% and Mehrgan et al., (2010) 47.1\%. High resistance to amoxicillin+clavulanic acid was seen with only $2.7 \%$ of ESBL producing $K$. pneumoniae isolates being susceptible. Similar observations were made by Mehrgan et al., (2010) $4.5 \%$ and Bishara et al., (2005) 5\% respectively. ESBL producing $K$. pneumoniae isolates were found to be $8.33 \%$ susceptibile to norfloxacin similar to Shobha et al., (2007) who reported 6\% susceptibility. High resistance to $\mathrm{III}^{\mathrm{rd}}$ generation cephalosporin, with only $0.9 \%$, $1.8 \%$ and $4.5 \%$ ESBL producing $K$. pneumoniae isolates being susceptibile to cefotaxime, ceftazidime and ceftriaxone, respectively. Similar observations were made by El Astal et al.,(2008) where none of the tested isolates were susceptible to cephalosporins and Mehrgan et al., (2010) who reported $0.6 \%, 1.9 \%, 0.6 \%$ susceptibility of cefotaxime, ceftazidime and ceftriaxone respectively while other studies showed variable higher susceptibility.

Among ESBL producer high rate of resistance to various antibiotics was seen (cefotaxime, ceftazidime, ceftriaxone, norfloxacin, cotrimoxazole). These high rates of resistance to various antibiotics may be due to various factors like-plasmid mediated transmission of ESBLs, poorly directed therapy and over-the-counter sales of antibiotics.

\section{Association of Risk Factors with Esbl Production}

In the present study total in 459 ESBL producing isolates, $144(31.37 \%)$ were isolated from patients with one or other type of serious illnesses followed by $112(24.4 \%)$ in old age patients, $93(20.26 \%)$ with prior exposure to antibiotics, $74(16.12 \%)$ with history of recent surgery, $68(14.81 \%)$ with invasive medical devices (urinary/arterial catheterization, central venous lines), 31 $(6.75 \%)$ with poorly nourished patient (anaemia, malnutrition), 21 (4.58\%) were associated with patient admitted in ICU, 09 $(1.96 \%)$ with intubated and mechanically ventilated patients and $08(1.74 \%)$ with urinary tract disease. All isolates recovered from ICU patients (21) and from intubated and mechanically ventilated (09) patients showed ESBL production.

Foley catheter, intravenous catheter, central venous catheter, intubation, surgery and mechanical ventilation were found as the risk factors for the acquisition of E. coli and $K$. pneumoniae with ESBLs Ozqunes et al., (2006). 
Chart.1 Flowchart for identification of Gram-negative lactose fermenting organisms

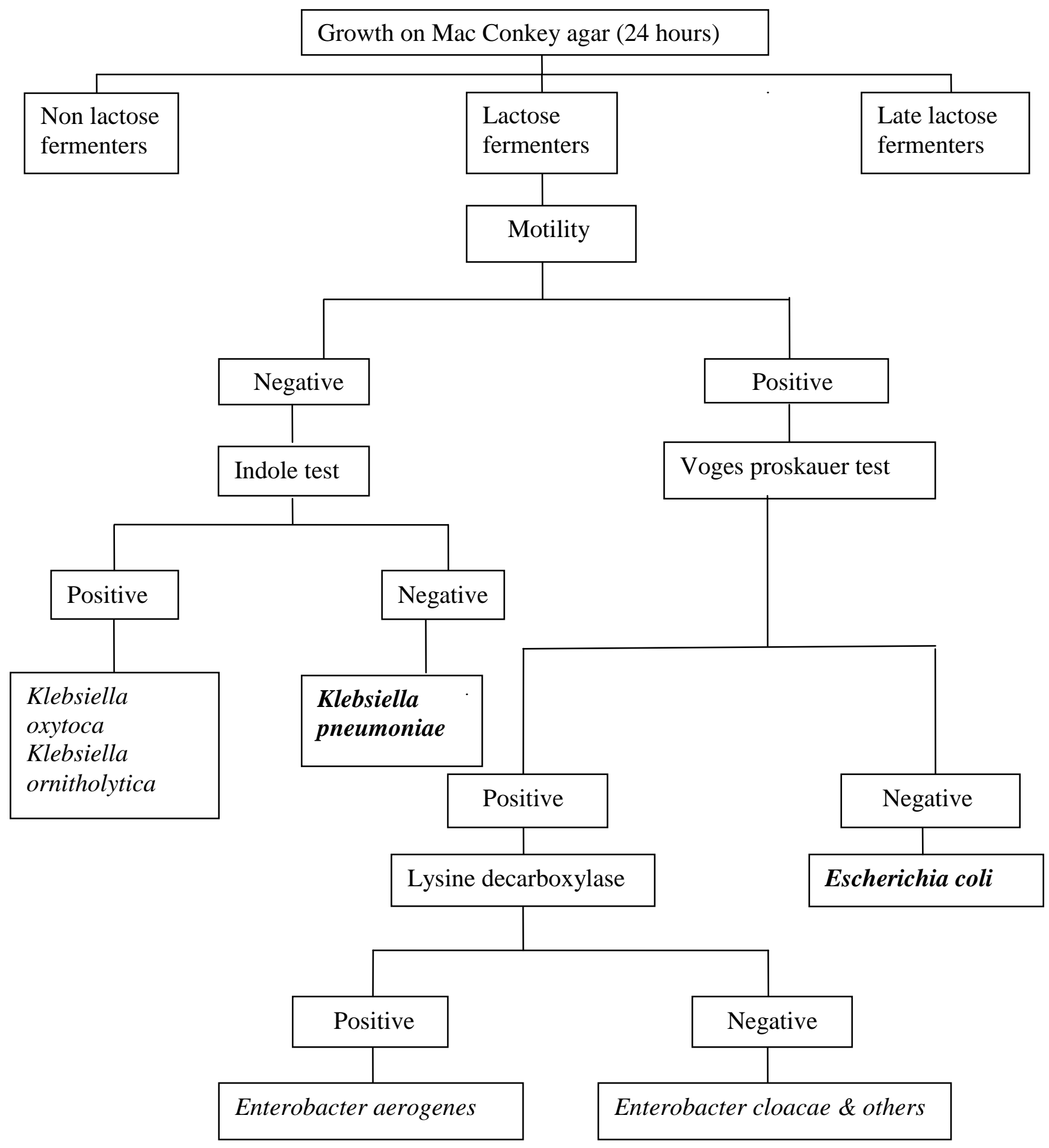


Table.1 Distribution of ESBL Producing Escherichia coli and Klebsiella pneumoniae.

\begin{tabular}{|c|l|c|c|c|}
\hline S. No & Organism & Total numbers & ESBL producers & Percentage (\%) \\
\hline 1 & Escherichia coli & 520 & 348 & $66.92 \%$ \\
\hline 2 & Klebsiella pneumoniae & 180 & 111 & $61.67 \%$ \\
\hline \multicolumn{2}{|c|}{ TOTAL } & 700 & 459 & $65.57 \%$ \\
\hline
\end{tabular}

Table.2 Distribution of ESBL producing and non ESBL producing Escherichia coli isolates from various clinical specimens

\begin{tabular}{|r|l|c|c|c|}
\hline S.N. & \multicolumn{1}{|c|}{ Clinical sample } & $\begin{array}{c}\text { Total E.coli isolate } \\
(\%)\end{array}$ & $\begin{array}{c}\text { E.coli ESBL positive } \\
\text { isolate }(\%)\end{array}$ & $\begin{array}{c}\text { E.coli ESBL negative } \\
\text { isolate }(\%)\end{array}$ \\
\hline 1. & Urine & $343(65.96 \%)$ & $217(62.36 \%)$ & $126(73.26 \%)$ \\
\hline 2. & $\begin{array}{l}\text { Sputum \& Respiratory tract } \\
\text { specimens }\end{array}$ & $59(11.35 \%)$ & $53(15.23 \%)$ & $06(3.49 \%)$ \\
\hline 3. & $\begin{array}{l}\text { Pus \& other wound } \\
\text { discharges }\end{array}$ & $65(12.50 \%)$ & $48(13.79 \%)$ & $17(9.88 \%)$ \\
\hline 4. & High vaginal swab & $21(4.04 \%)$ & $11(3.16 \%)$ & $10(5.81 \%)$ \\
\hline 5. & Stool & $07(1.35 \%)$ & $06(1.72 \%)$ & $01(0.58 \%)$ \\
\hline 6. & Body fluids & $02(0.38 \%)$ & $01(0.29 \%)$ & $01(0.58 \%)$ \\
\hline 7. & Blood & $03(0.58 \%)$ & $03(0.86 \%)$ & $00(0.00 \%)$ \\
\hline 8. & Others & 520 & 348 & 172 \\
\hline 9. & TOTAL & & $09(2.59 \%)$ & $110 \%)$ \\
\hline
\end{tabular}

Table.3 Distribution of ESBL producing and non ESBL producing Klebsiella pneumoniae isolates from various clinical Specimens

\begin{tabular}{|r|l|c|c|c|}
\hline S.N. & \multicolumn{1}{|c|}{ Clinical sample } & $\begin{array}{c}\text { Total K. pneumoniae } \\
\text { isolate }(\%)\end{array}$ & $\begin{array}{c}\text { K. pneumoniae } \\
\text { ESBL positive isolate } \\
(\%)\end{array}$ & $\begin{array}{c}\text { K. pneumoniae } \\
\text { ESBL negative isolate } \\
(\%)\end{array}$ \\
\hline 1. & Urine & $75(41.67 \%)$ & $36(32.43 \%)$ & $39(56.52 \%)$ \\
\hline 2. & $\begin{array}{l}\text { Sputum \& Respiratory tract } \\
\text { specimens }\end{array}$ & $50(27.78 \%)$ & $30(27.03 \%)$ & $20(28.99 \%)$ \\
\hline 3. & $\begin{array}{l}\text { Pus \& other wound } \\
\text { discharges }\end{array}$ & $35(19.44 \%)$ & $29(26.13 \%)$ & $06(8.70 \%)$ \\
\hline 4. & Blood & $08(4.44 \%)$ & $07(6.31 \%)$ & $01(1.45 \%)$ \\
\hline 5. & Body fluids & $05(2.78 \%)$ & $04(3.60 \%)$ & $01(1.45 \%)$ \\
\hline 6. & High vaginal swab & $04(2.22 \%)$ & $03(2.70 \%)$ & $01(1.45 \%)$ \\
\hline 7. & Stool & $01(0.56 \%)$ & $01(0.90 \%)$ & $00(0.00 \%)$ \\
\hline 8. & Others & $02(1.11 \%)$ & $01(0.90 \%)$ & $01(1.45 \%)$ \\
\hline 9. & TOTAL & 180 & 111 & 69 \\
\hline
\end{tabular}


Table.4 Antimicrobial Susceptibility pattern of ESBL producing and non- ESBL producing E .coli

\begin{tabular}{|c|l|c|c|}
\hline S.N. & Antibiotics & $\begin{array}{l}\text { E. coli ESBL positive } \\
\text { isolate }(\%)\end{array}$ & $\begin{array}{l}\text { E. coli ESBL negative } \\
\text { isolate }(\%)\end{array}$ \\
\hline 1. & Amikacin (AK) & $210(60.35 \%)$ & $139(80.81 \%)$ \\
\hline 2. & Amoxicillin+Clavulanic acid (AC) & $113(32.5 \%)$ & $105(61.05 \%)$ \\
\hline 3. & Cefotaxime (CE) & $01(0.29 \%)$ & $169(98.26 \%)$ \\
\hline 4. & Ceftazidime (CA) & $00(0.00 \%)$ & $170(98.84 \%)$ \\
\hline 5. & Ceftriaxone (CI) & $03(0.86 \%)$ & $167(97.09 \%)$ \\
\hline 6. & Cotrimoxazole (CO) & $39(11.21 \%)$ & $46(26.74 \%)$ \\
\hline 7. & Doxycycline hydrochloride (DO) & $70(20.11 \%)$ & $55(31.97 \%)$ \\
\hline 8. & Gatifloxacin (GF) & $179(51.44 \%)$ & $122(70.93 \%)$ \\
\hline 9. & Imipenem (I) & $348(100 \%)$ & $172(100 \%)$ \\
\hline 10. & Meropenem (MR) & $348(100 \%)$ & $172(100 \%)$ \\
\hline 11. & Nitrofurantoin (NF) & $150(69.12 \%)$ & $108(85.71 \%)$ \\
\hline 12. & Norfloxacin (NX)* & $02(0.92 \%)$ & $32(25.40 \%)$ \\
\hline
\end{tabular}

* Norfloxacin and nitrofurantoin were tested against urinary isolates only.

Table.5 Antimicrobial Susceptibility pattern of ESBL producing and non-ESBL producing K. pneumonia

\begin{tabular}{|c|l|c|c|}
\hline $\begin{array}{l}\text { S. } \\
\text { N. }\end{array}$ & Antibiotics & $\begin{array}{l}\text { K. pneumoniae ESBL } \\
\text { positive isolate (\%) }\end{array}$ & $\begin{array}{l}\text { K. pneumoniae ESBL } \\
\text { negative isolate (\%) }\end{array}$ \\
\hline 1. & Amikacin (AK) & $62(55.86 \%)$ & $55(79.71 \%)$ \\
\hline 2. & Amoxicillin+Clavulanic acid (AC) & $03(2.70 \%)$ & $33(47.83 \%)$ \\
\hline 3. & Cefotaxime (CE) & $01(0.90 \%)$ & $68(98.55 \%)$ \\
\hline 4. & Ceftazidime (CA) & $02(1.80 \%)$ & $67(97.10 \%)$ \\
\hline 5. & Ceftriaxone (CI) & $05(4.50 \%)$ & $65(94.20 \%)$ \\
\hline 6. & Cotrimoxazole (CO) & $06(5.41 \%)$ & $25(36.23 \%)$ \\
\hline 7. & Doxycycline hydrochloride (DO) & $30(27.03 \%)$ & $30(43.47 \%)$ \\
\hline 8. & Gatifloxacin (GF) & $70(63.06 \%)$ & $57(82.60 \%)$ \\
\hline 9. & Imipenem (I) & $111(100 \%)$ & $69(100 \%)$ \\
\hline 10. & Meropenem (MR) & $111(100 \%)$ & $69(100 \%)$ \\
\hline 11. & Nitrofurantoin (NF) & $24(66.67 \%)$ & $34(87.18 \%)$ \\
\hline 12. & Norfloxacin (NX) & $03(8.33 \%)$ & $18(46.15 \%)$ \\
\hline
\end{tabular}

*Norfloxacin and nitrofurantoin were tested against urinary isolates only. 
Table.6 Association of risk factors with ESBL production

\begin{tabular}{|c|c|c|c|}
\hline S.N. & Risk factors & $\begin{array}{l}\text { ESBL positive } \\
\text { isolate }(\%)\end{array}$ & $\begin{array}{l}\text { ESBL negative } \\
\text { isolate }(\%)\end{array}$ \\
\hline 1. & Prior exposure to antibiotics & $93(20.26 \%)$ & $06(2.49 \%)$ \\
\hline 2. & ICU stay & $21(4.58 \%)$ & $00(0.00 \%)$ \\
\hline 3. & Severe illness & $144(31.37 \%)$ & $17(7.05 \%)$ \\
\hline 4. & $\begin{array}{l}\text { Invasive medical devices (urinary/arterial catheterization, central } \\
\text { venous lines) }\end{array}$ & $68(14.81 \%)$ & $15(6.22 \%)$ \\
\hline 5. & Intubation \& Mechanical ventilation & $09(1.96 \%)$ & $00(0.00 \%)$ \\
\hline 6. & Recent surgery & $74(16.12 \%)$ & $13(5.39 \%)$ \\
\hline 7. & Old age $(>60$ year $)$ & $112(24.4 \%)$ & $59(24.48 \%)$ \\
\hline 8. & Poor nutritional status & $31(6.75 \%)$ & $5(2.07 \%)$ \\
\hline 9. & $\begin{array}{l}\text { Urinary tract pathology (Polycystic kidney disease, Renal/Bladder } \\
\text { calculi, Stricture urethra) }\end{array}$ & $08(1.74 \%)$ & $02(0.83 \%)$ \\
\hline
\end{tabular}

Lautenbach (2001) et al., observed that the prior antibiotic use and longer duration of hospital stay were the risk factor for ESBLproducing $\mathrm{E}$. coli or $\mathrm{K}$. pneumoniae infection.

As ESBL-positive isolates occur in large number of patients and show false susceptibility to expanded-spectrum cephalosporins in standard disk diffusion test, therefore care should be taken by not giving cephalosporins and aztreonam, regardless of the routine susceptibility test results.

In conclusion, Escherichia coli $(66.92 \%)$ were found to be more extended spectrum $\beta$ lactamase producer than Klebsiella pneumoniae $(61.67 \%)$, this may be peculiar to Indian subcontinent. The antimicrobial resistance was significantely higher in ESBL producer than non-ESBL producer.Among Extended spectrum $\beta$ - lactamase producing isolates imipenem and meropenem was most sensitive followed by nitrofurantoin, amikacin and gatifloxacin. Least sensitive antibiotic were cephalosporins (cefotaxime, ceftazidime, ceftriaxone). The risk factors involved in acquisition of ESBL production in the present study were:- severe illness, prior exposure to antibiotics, recent surgery, invasive medical device (urinary catheterization), poor nutritional status, ICU stay, intubation and mechanical ventilation respectively. Therefore clinician should take adequate measures in treating the patients with risk factors.

\section{References}

Agrawal, P., Ghosh, A.N., Kumar, S., Basu, B., Kapila, K. 2008. Prevalence of extended- spectrum $\beta$-lactamases among Escherichia coli and Klebsiella pneumoniae isolates in a tertiary care hospital. Indian J. Pathol. Microbiol., 51: 139-142.

Al-Zarouni, M,. Senok, A., Rashid, F., AlJesmi, S.M., Panigrahi, D. 2008. Prevalence and antimicrobial susceptibility pattern of ESBL producing Enterobacteriace in United Arab Emirates. Medical Principle and Practice, 17: 32-36.

Bishara, J., Livne, G., Ashkenaz,i S., Levy, I., Pitlik, S., Ofir, O., Lev, B., Samara, Z. 2005. Antibacterial susceptibility of ESBL producing Klebsiella pneumoniae and Escherichia coli. IMAJ, Vol 7:298-300.

Bradford, P.A. 2001. ESBL in the 21st Century: Characterization, Epidemiology, and Detection of This Important Resistance threat. Clin. Microbiol. Rev., 14(4):933-951. 
Briggs, S., Ussher, J., Taylor, S. 2005. Extended-spectrum $\quad \beta$-lactamases producing Enterobacteriace at Middle More Hospital. J. New Zealand Med. Assoc., Vol 118, No 1218.

Chaudhary, U., Aggarwal, R. 2004. Extended spectrum $\beta$-lactamases (ESBL) - An emerging threat to clinical therapeutics. Indian J. Med. Microbiol., 22(2): 75-80.

Clinical and Laboratory Standards Institute (CLSI), M100 - S23, Performance Standards for Antimicrobial Susceptibility Testing; Twenty- Third Informational Supplement

El Astal, Z.Y., Ramadan, H. 2008. Occurence of ESBL isolate of Klebsiella pneumoniae and Escherichia coli. Int. J. Integrative Biol., Vol 2, No 2, 122127.

Fazlay Bazzaz, B.S., Naderinasab, M., Mohamadpoor, .A.H, Farshadzadeh, Z., Ahmadi, S., Yousefi, F. 2009. Prevalence of extended-spectrum betalactamase-producing Escherichia coli and Klebsiella pneumoniae among clinical isolates from a general hospital in Iran. Acta Microbiologica et Immunologica Hungarica, 56 (1), pp. 89-99. $\quad$ DOI: $\quad 10.1556 / A$ Micr.56.2009.1.7

Gupta, V., Datta, P. 2007. Extended-spectrum beta-lactamases (ESBL) in community isolates from North India: frequency and predisposing factors. Int. J. Infect. Dis., 11(1):88-89.

Kader, A.A., Kumar, A. 2005. Prevalence and antimicrobial susceptibility of ESBL producing Escherichia coli and Klebsiella pneumoniae in a general Hospital. Ann. Saudi Med., 25(3): 239242.

Shobha, K.L., Rao, G., Rao, S., Sreeja, C.K. 2007. Prevalence of Extended Spectrum Beta-Lactamases in Urinary Isolates of Escherichia coli, Klebsiella and Citrobacter Species and their Antimicrobial Susceptibility Pattern in a Tertiary Care Hospital. Indian $J$.
Practising Doctor, Vol. 3, No. 6 (200701 - 2007-02) ISBN: 0973-516X.

Kumar, M.S., Lakshmi, V., Rajagopalan, R. 2006. Occurrence of ESBL among Enterobacteriace spp. isolated at a tertiary care institute. Indian J. Med. Microbiol., 24(3): 208-211.

Kusum, M., Wongwanich, S., Dhiraputra, C., Pongpech, P., Naenna, P. 2004. Occurrence of extended-spectrum betalactamase in clinical isolates of Klebsiella pneumoniae in a University Hospital, Thailand. J. Med. Assoc. Thai, 87(9): 1029-1033.

Lautenbach, E., Patel, J.B., Bilker, W.B., Edelstein, P.H. and Fishman, N.O. 2001. Extended-Spectrum $\beta$-LactamaseProducing Escherichia coli and Klebsiella pneumoniae: Risk Factors for Infection and Impact of Resistance on Outcomes. Clin. Infect. Dis., Vol. 32, No. 8 (Apr. 15, 2001), pp. 1162-1171.

Mehrgan, H., Rahbar, M., Arab-Halvaii, Z. 2010. High prevalence of extendedspectrum beta-lactamase-producing Klebsiella pneumoniae in a tertiary care hospital in Tehran, Iran J. Infect. Dev. Ctries,4(3): 132-138.

Mohanty, S., Kapil, A., Das, B.K., Dhawan, B. 2003. Antimicrobial resistance profile of nosocomial uropathogens in a tertiary care hospital. Indian J. Med. Sci., 57: 148-154.

Ozgunes, I., Erben, N., Kiremitchi, A., Kartal, E.D., Durmaz, G., Colak, H., Usleur, G., Colak, E. 2006. The Prevalence of extended-spectrum $\quad \beta$-lactamases producing Escherichia coli and Klebsiella pneumoniae in clinical isolates and risk factors. Saudi Med. J., 27(5): 608-612.

Puberza, R., Selderina, S., Leja, S., Storozenko, J., Luzbinska, L, Zievica, A. 2007. Prevalence of extendedspectrum $\quad \beta$-lactamases producing Enterobacteriace strain in Lativa. Bioautomation, 99-103, ISSN 1312$451 \mathrm{X}$ 
Rajini, .E, Sherwal, B.L., Anuradha. 2008. Detection of Extended-Spectrum $\beta$ lactamases in AmpC $\beta$-lactamaseProducing Nosocomial Gram-negative Clinical Isolates from a Tertiary Care Hospital in Delhi. Indian J. Practising Doctor, Vol. 4, No. 6 (2008-01 - 200802) ISSN: 0973-516X

Rodrigues, C., Joshi, P., Jani, S.H., Alphonse, M., Radhakrishnan, R., Mehta, A. 2004. Detection of $\beta$-lactamases in nosocomial gram-negative clinical isolates. Indian J. Med. Microbiol., 22 (4): 247-250.

Sasirekha, B., Manasa, R., Ramya, P., Sneha, R. 2010. Frequency and antimicrobial sensitivity pattern of Extended $\beta$ Lactamase producing E.coli and K. pneumoniae isolated in a tertiary care hospital. Al Ameen J. Med. Sci., 3(4): 265-271.

Shobha, K..L, Ramachandra, L., Rao, G., Majumder, S., Rao, S.P. 2009. Extended-spectrum $\quad \beta$-lactamases in gram negative bacilli at a tertiary care hospital. J. Clin. Diag. Res., 3: 13071312.

Singhal, S., Mathur, T., Khan, S., Upadhyay, D.J., Gaind, R., Rattan, A. 2005. Evaluation of methods for Amp-C $\beta$ Lactamases in gram-negative clinical isolates from tertiary care Hospital. Indian J. Med. Microbiol., 23(2): 120124.

Subha, A., Ananthan, S. 2002. Extended spectrum beta lactamase (ESBL) mediated resistance to third generation cephalosporins among Klebsiella pneumoniae in Chennai. Indian J. Med. Microbiol., 20(2): 92-95.

Tsering, D.C., Das, S., Adhiakari, .L, Pal, R., Singh, T.S. 2009. Extended spectrum beta-lactamase detection in gramnegative bacilli of nosocomial origin. $J$. Global Infect. Dis., 1: 87-92.

Varaiya, A., Dodra, J., Kulkarni, M., Bhaleker, P. 2008. ESBL producing Escherichia coli and Klebsiella pneumoniae in diabetic foot infection. Indian J. Med. Microbiol., 26(3):281282

Waiwarawooth, J., Jutiworakul, K., Joraka, W. 2006. The Prevalence and Susceptibility Patterns of ESBL-producing Klebsiella pneumoniae and Escherichia coli in Chonburi Hospital. J. Infect. Dis. Antimicrob. Agents, 23: 57-65.

Wani, K.A., Thakur, M.A,. Siraj Fayaz, A., Fomdia, B., Gulnaz, B., Maroof, P. 2009. Extended Spectrum $\beta$-Lactamase Mediated Resistance in Escherichia coli in a Tertiary Care Hospital. Int. J. Health Sci., Qassim University, Vol. 3, No.2, (July 2009/Jamada II 1430H) : 155-168.

Winn, W.C., Jr, Allen, S.D., Janda, W.M., Koneman, E.W., Procop, G.W., Schreckenberger, P.C., Woods, G.L. 2006. Koneman's color atlas and text book of diagnostic Microbiology. 6th ed. Philadelphia: LIPPINCOTT WILLIAMS \& WILKINS, p.1003.

\section{How to cite this article:}

Bhagirath Ram Bishnoi, Abhishek Binnani and Priyanka Soni Gupta. 2016. Prevalence and Antimicrobial Susceptibility Pattern of Extended Spectrum Beta-Lactamse Producing Escherichia coli and Klebsiella pneumoniae Isolated at a Tertiary Care Institute in North West Region of Rajasthan, India. Int.J.Curr.Microbiol.App.Sci. 5(7): 912-923. doi: http://dx.doi.org/10.20546/ijcmas.2016.507.103 